\title{
An automated standard-based life cycle quality inspection methodology for smart precast concrete solutions in buildings
}

Magdalena Hajdukiewicz, Jamie Goggins, Oscar de la Torre, Dave Holleran \& Marcus M. Keane

To cite this article: Magdalena Hajdukiewicz, Jamie Goggins, Oscar de la Torre, Dave Holleran \& Marcus M. Keane (2019) An automated standard-based life cycle quality inspection methodology for smart precast concrete solutions in buildings, Journal of Structural Integrity and Maintenance, 4:3, 123-134, DOI: 10.1080/24705314.2019.1627454

To link to this article: https://doi.org/10.1080/24705314.2019.1627454

Published online: 29 Jul 2019.

Submit your article to this journal ¿

View Crossmark data ¿ 


\title{
An automated standard-based life cycle quality inspection methodology for smart precast concrete solutions in buildings
}

\author{
Magdalena Hajdukiewicz, ${ }^{\mathrm{a}, \mathrm{b}, \mathrm{d}, \mathrm{d}}$, Jamie Goggins ${ }^{\mathrm{a}, \mathrm{b}, \mathrm{c}, \mathrm{d}}$, Oscar de la Torre ${ }^{\mathrm{e}}$, Dave Holleran ${ }^{\mathrm{f}}$ and Marcus M. Keane $\mathrm{e}^{\mathrm{a}, \mathrm{b}, \mathrm{c}}$ \\ aCivil Engineering, College of Engineering and Informatics, National University of Ireland, Galway, Ireland; bInformatics Research Unit for \\ Sustainable Engineering (IRUSE), Galway, Ireland; 'Ryan Institute, National University of Ireland, Galway, Ireland; dMaREl Centre for Marine and \\ Renewable Energy, Galway, Ireland; eSchool of Engineering, University of Plymouth, Plymouth, UK; fOran Pre-Cast Ltd., Oranmore, Ireland
}

\begin{abstract}
Built2Spec research project brought together a new and breakthrough set of tools in order to improve construction quality inspection processes. These can be put into the hands of construction stakeholders to help meet Europe's energy efficiency targets, standards for constructing and retrofitting buildings, and related policy ambitions. This paper focuses on the automated standard-based life cycle quality inspections for precast concrete structural building elements that can be enhanced by leveraging a range of different technologies. Particular attention is placed on the use of embedded sensors in the precast concrete structural building elements as a tool to support quality assurance of these elements. Starting with the design, through manufacturing, delivery to site, installation, commissioning and operation until the end of life, the performance of precast concrete building elements is monitored and controlled to ensure their compliance with specifications, standards and guidelines. The outputs of proposed technologies integrated within the virtual construction management platform (VCMP) can enable automated continuous quality checks, while making them accessible to stakeholders through the life of a building. The measurements to support the development of this methodology were provided by a newly constructed demonstration building in Ireland.
\end{abstract}

\section{KEYWORDS}

Quality checks; smart construction; precast concrete; embedded sensors; methodology; quality assurance

\section{Introduction}

\section{Overview}

Statistics show that construction and the upkeep of buildings and infrastructure are the largest industry worldwide accounting for approximately $10 \%$ of global gross domestic product (GDP) (ECTP, 2012). Furthermore, it is well documented that the built environment in Europe accounts for more than $40 \%$ of the overall energy consumption and $36 \%$ of the overall $\mathrm{CO}_{2}$ emissions (PérezLombard, Ortiz, \& Pout, 2008). Concerning the problem of inefficient energy consumption in the building sector in general, the European Union (EU) adopted the Directive 2010/31/EU (European Commission, 2010). According to the Directive, member states are required to adopt a methodology for calculating the energy performance of buildings (i.e. energy performance certification). Furthermore, the Directive will ensure that in the EU, all new buildings or those receiving significant retrofit must be almost zero-energy consumption buildings by the end of 2020. In order to meet the requirements posed by the EU and, thus, reduce the environmental impact of buildings, energy efficient measures must be taken into account when designing new and retrofitting existing buildings. In the architecture, engineering and construction (AEC) industry, international standards are enshrined in law and regulations to ensure quality, e.g. through national building regulations. Thus, it is critical that design, manufacturing and construction processes comply with the standard-based quality inspections.

\section{Built2spec project}

In order to improve construction quality inspection processes, the "Built2Spec - Tools for the $21^{\text {st }}$ century construction site" project (Built2Spec project, 2015) brought together a new and breakthrough set of technological advances for quality inspection and assurance that can be put into the hands of construction stakeholders (e.g. site managers, contractors, quantity surveyors, building managers, etc.) to help meet Europe's energy efficiency targets, standards for constructing and retrofitting buildings, and related policy ambitions.

The centrepiece of the Built2Spec project was a cloudbased virtual construction management platform (VCMP), which hosted applications that facilitate worksite activities and quality compliance by putting knowledge in the hands of contractors. This was done through shared design specifications and 3D digital models, installation guidelines, information on regulatory frameworks and support from construction experts on smartphones and tablets, from initial design to delivery.

This paper focuses on the automated standard-based life cycle quality inspections for precast concrete structural building elements that can be enhanced by leveraging a range of different technologies. Particular attention is placed on the use of embedded sensors in the precast concrete structural building elements as a tool to support the quality assurance of these elements. Using strain gauges and thermistors cast into building structural elements (such as slabs), the structural and environmental performance of the building can be continuously monitored not only at the construction stage, but through the entire life cycle of the building. 


\section{Literature review}

\section{Concrete as a building material}

Concrete is a durable building material that requires very limited maintenance, replacement or application of toxic paints or preservatives. Moreover, the thermal capacity of concrete leads to thermal stability and, thus, offers considerable energy savings and good quality of indoor environment. Hence, concrete is the primary construction material in many sustainable developments in Europe (IPCA, 2005).

Precast reinforced and pre-stressed concrete is widely regarded as an economic, structurally sound and architecturally versatile building material. Controlled and cost-effective manufacturing processes guarantee high-quality products at a reduced cost and a minimum design/manufacturing/construction time. Despite the popularity of concrete as a building material in Europe, as well as its well-known structural properties, there is a dearth of research available on the interaction between the building structure and indoor environments to support energy efficient solutions in buildings. Furthermore, since defects occurring during the construction processes are costly and detecting them manually can be time consuming, there is a potential for advanced technologies to aid in quality control during construction processes.

\section{Embedded sensors}

Sensors can be embedded in structural elements in order to improve quality control and assurance of structures. The main objective for embedding sensors in structures is structural health monitoring (SHM) during their construction and operation. Embedded sensors have been increasingly used, particularly in the last two decades, for long-term SHM of full-scale civil infrastructures (Brownjohn, 2007), such as underground structures (e.g. (Coutts, Wang, \& Cai, 2001)), bridges/viaducts (e.g. (Lynch et al., 2004)) and dams (e.g. (Darbre \& Proulx, 2002)). The SHM has started with performance monitoring of structures in seismically active regions (e.g. (Mita, 1999)). However, work has also been done in embedding sensors in particular building elements to investigate their long-term structural behaviour, e.g. (Hajdukiewicz, Byrne, Keane, \& Goggins, 2015; Li, Ren, Jia, Yi, \& Li, 2016; Newell, Hajdukiewicz, \& Goggins, 2016). This includes performance monitoring during the construction process, e.g. (Uva, Porco, Fiore, \& Porco, 2014).

Different properties, including temperature (e.g. (Ranz, 2016)), moisture content/penetration (e.g. (McCarter \& Chrisp, 2000)), pH (e.g. (Nguyen et al., 2014)) or reinforcement corrosion (e.g. (Mao et al., 2015)), etc., can greatly influence the performance of reinforced concrete.

The traditional types of sensors used in SHM include vibrating wire (VW) strain gauges and electrical resistance strain gauges. The VW gauges are robust, can operate in the harsh concrete environment and are one of the most utilised strain sensors in monitoring buildings and infrastructure (Lee, Kim, Sho, \& Park, 2010). Embedding electrical resistance strain gauges in concrete works well for measuring shortterm strains in embedded steel, but are not suitable for longterm monitoring due to electromagnetic interference and the potential of corrosion of gauges and lead wires.

Furthermore, in the last number of years, research has been focusing on the development and deployment of fibre optics in civil and structural engineering, e.g. (Li, Li, \& Song, 2004). Fibre optics are known to have higher (than VW gauges) resolution and accuracy (Lee et al., 2010), but are also currently more expensive. All of the above-mentioned technologies require cables to connect the sensors to the data acquisition unit. However, in recent years, there has been work done to enable wireless SHM, e.g. (Ha, Park, Kim, \& Park, 2014; Lynch, 2007; Lynch et al., 2004).

\section{Tags}

The need for implementing lean production standards and manufacturing systems based on just-in-time philosophy made time an asset that should be constantly controlled. Building manufacturing has not embraced this philosophy in general. However, some efforts have been made in this direction, e.g. (Matt, Dallasega, \& Rauch, 2014).

In order to improve logistics and support lean production/manufacturing, identification or tag sensors can be instrumental, e.g. (Wu, Low, \& Jin, 2013). Those sensors have been intensively used in the automotive and other industries for years. However, they are now gaining popularity in the building industry as tracking systems.

Radio frequency identification (RFID) sensors have been used previously to track precast concrete components (Ergen, Akinci, \& Sacks, 2007) and tools on a construction site (Goodrum, McLaren, \& Durfee, 2006), and to improve just-in-time delivery (Ergen et al., 2007). The RFID can be utilised in precast concrete quality management systems (Yin, Tserng, Wang, \& Tsai, 2009), allowing for information, such as production quality, material quantities, inventory, logistics management and quality inspection, to be transmitted to a manager (or any on-site personnel) via a personal digital assistant to enhance supply chain management and quality control (Sørensen, Christiansson, \& Svidt, 2009). Valero and Adán (2016) produced an interesting review of the evolution of RFID technology at different stages of the construction process.

\section{D scanning}

Amongst all the technologies shown here, the 3D scanning appears as the most mature when applied to the construction industry. There exists a whole body of literature dealing with 3D scanning applications at different construction stages. 3D scanning is a relatively common tool for evaluating the displacement of structures (e.g. bridges (Chase, 2001) or retaining walls (Oskouie, Becerik-Gerber, \& Soibelman, 2016)) or to recognise potential deviations between asdesigned and as-built structures, e.g. (Bosché, 2010).

\section{BIM}

Building information modelling (BIM) has shown its benefits over the more traditional and only geometrical computeraided design (CAD) models. For this reason, BIM is becoming a standard technology and process in the architecture, engineering and construction industry. Previous research has shown that BIM can be very useful in integrating construction processes documentation (e.g. Aram, Eastman, \& Sacks, 2013; Chen, Lu, Peng, Rowlinson, \& Huang, 2015; Goedert \& Meadati, 2008). It has been also shown that when the objectives of BIM are widened or when BIM models are shared 
between different users, e.g. (Jeong, Eastman, Sacks, \& Kaner, 2009; Lee, Eastman, \& Solihin, 2016), some compatibility problems may arise. However, the general trend in the industry is to utilise BIM data for purposes that will push the industry forward and potentially reduce compatibility problems currently arising.

\section{Combined technologies}

As precast concrete technology has become more popular within the construction industry, the speed of construction process has also increased. Due to this increased pace of construction, a high efficiency in the assessment of as-built precast concrete surface and dimensional specification is needed. The quality checks must be done to prevent failure of elements; however, the inspection process cannot delay the project progress. Combining 3D scanning technology with BIM data, e.g. (Kim et al., 2016), allows (i) the development of automatic techniques to evaluate dimensional quality of precast concrete elements and (ii) the management of data through BIM.

The process of manually updating information in a BIM can generate errors and can be time consuming (Anil, Tang, Akinci, \& Huber, 2013). Thus, research in recent years has focused on developing technologies that can be integrated with BIM during construction process. Automatic identification, such as barcoding or RFID, combined with BIM has been proposed previously to track, trace and control the construction projects (Flanagan, Jewell, Lu, \& Pekericli, 2014). Furthermore, emerging sensing technologies and modelling capabilities motivated the development of quality control approaches, through acquiring and updating detailed design information, identifying inspection goals, inspection planning, as-built data acquisition and analysis, and defect detection and management (Akinci et al., 2006).

\section{Methodology}

\section{Automated standard-based life cycle quality inspections}

Precast concrete solutions offer reduced construction times and higher quality finishes than typical-reinforced concrete structures. A set of harmonised structural design codes for buildings are included in the Eurocodes (CEN, 1999), which:

- Establish principles and requirements for the safety, serviceability and durability of structures, describe the basis for their design and verification, and give guidelines for related aspects of structural reliability,

- Provide comprehensive information on all actions that should normally be considered in the design of buildings and other civil engineering works, including some geotechnical aspects,

- Are concerned with the requirements for resistance, serviceability, durability and fire resistance of concrete structures.

The quality assurance linked to standards, during the manufacturing and construction of precast concrete building elements, is crucial to ensure the designed structural performance of the building, guaranteeing the safety of the construction workers and future building occupants. Currently, the majority of the quality inspections are performed manually, which can be time consuming. Thus, there is a potential for advanced technologies to aid in automated quality control during manufacturing and construction processes.

Table 1 describes a process workflow of quality checks for smart precast concrete solutions through the full building life cycle, and shows how these quality checks can be automated through the virtual construction management platform (VCMP). The research presented here focuses on sensor embedded precast concrete solutions. However, other technologies, such as tags, BIM and 3D scanning techniques, are also proposed to enhance the process of quality checks during the life cycle of precast concrete solutions.

The performance criteria for data measurement act as input requirements to the integrated VCMP. These measurements may include geometry, dimensions, location, concrete temperature and strain, all critical data for evaluating precast/in situ system performance.

The BS EN ISO 9001:2008 Quality Management Systems standard (ISO, 2008) specifies systematic quality checking procedures that support the development of products that comply with customer and regulatory requirements. This research addresses the need for continuous quality checks of building elements through their life cycle. Thus, the environmental/ structural monitoring of smart precast concrete solutions commences at the manufacturing stage of the precast element, through the on-site installation and continues during the building commissioning and operation, and is underpinned by recognised quality management standards. The continuous monitoring and inspection of the data allows element/system performance to be continuously checked with design intent, standards and guidelines (Figure 1).

\section{Demonstration - human biology building (HBB)}

The measurements to support the development of the performance database for the standard-based life cycle quality inspection methodology for smart precast concrete solutions are provided by a newly constructed demonstration building, the Human Biology Building (HBB) (Figure 2), at the National University of Ireland (NUI), Galway in Ireland. This four-storey building (over basement and roof-level plant enclosure), with a gross floor area of $8,200 \mathrm{~m}^{2}$, is a teaching and research facility with lecture theatres, laboratories, offices and meeting rooms. Construction commenced in January 2015 and the building started its operation in September 2017.

HBB was designed and constructed predominantly in the precast concrete technology, including the building frame, twinwall system, hybrid concrete lattice girder slabs and hollowcore slabs. Embedded sensors were positioned in the two-way spanning second/third floor of the HBB in two zones (East and West wing of the building, Figure 3) to monitor the strain and temperature in the concrete floor structure (hybrid concrete lattice girder flat slab, Figure 4) during the construction and operational phases of the building. The overall thickness of the floor slabs was $400 \mathrm{~mm}$, and consisted of a $65 \mathrm{~mm}$ thick precast lattice girder planks and $335 \mathrm{~mm}$ in situ concrete topping.

Complete performance database for smart precast concrete solutions will consist of the BIM (in the industry foundation classes (IFC) data format), numerical models (finite element (FE) and computational fluid dynamics (CFD)) and real-time physical data (on-site measurements and 
Table 1. Concept of quality checks for smart precast concrete solutions (Built2Spec project, 2017a).

\begin{tabular}{|c|c|c|}
\hline & $\begin{array}{l}\text { Ailding life cycle } \\
\text { stage }\end{array}$ & Quality checks \\
\hline 1 & Design & $\begin{array}{l}\text { Engineer designs a precast concrete element based on the (i) specifications, (ii) design standards and guidelines, and (iii) numerical } \\
\text { and/or analytical models (structural and environmental). Specifications and results of the numerical models required for further } \\
\text { quality checks (e.g. designed strength of concrete or temperature profiles) are uploaded to VCMP. } \\
\text { The BIM of the precast concrete element is developed and it is assigned a specific ID code (this code will later link the data } \\
\text { collected from the physical element with the BIM and other information within the VCMP). The BIM (as designed) is uploaded to } \\
\text { the VCMP. } \\
\text { Specifications regarding the type, number and location of sensors to be embedded in the precast concrete element are uploaded } \\
\text { to VCMP. }\end{array}$ \\
\hline 2 & Manufacturing & $\begin{array}{l}\text { Precast element BIM (as designed) is sent to the manufacturing line where the production of the precast concrete element starts. } \\
\text { Sensor specifications are available to the manufacturing team through the VCMP. } \\
\text { - Tags (e.g. barcode or RFID) are used to monitor the progress of the manufacturing process (e.g. to support lean manufacturing). } \\
\text { Once a particular stage of element manufacturing is completed (such as shuttering, reinforcement, concrete pour), the tag is } \\
\text { scanned } \rightarrow \text { VCMP notification ELEMENT READY. }\end{array}$ \\
\hline $2 a$ & Shuttering & $\begin{array}{l}\text { The first step of the precast concrete element manufacturing is the placement of the shuttering. } \\
\text { - Dimensions and angles of the shuttering are scanned using a high accuracy 3D scanner. The 3D scans are then compared with } \\
\text { the BIM, in order to perform this quality check } \rightarrow \text { VCMP notification PASS or FAIL. }\end{array}$ \\
\hline $2 b$ & Reinforcement & $\begin{array}{l}\text { The next step of the precast concrete element manufacturing is the placement of the reinforcement. } \\
\text { - Number of reinforcement bars, diameter and distances are checked using the high accuracy 3D scans compared with the BIM } \\
\rightarrow \text { VCMP notification PASS or FAIL. }\end{array}$ \\
\hline $2 c$ & Concrete pour & $\begin{array}{l}\text { The final step of the precast element manufacturing is the concrete pour. } \\
\text { - Overall dimensions of the element and the quality of the surface are checked using the } \mathbf{3 D} \text { scans compared with the BIM } \rightarrow \\
\text { VCMP notification PASS or FAIL. } \\
\text { - Utilising embedded sensors (i.e. thermistors) at this stage of the element manufacturing allows for concrete temperature } \\
\text { measurement to assess if the strength gain in concrete is according to the design specifications. The comparison of the } \\
\text { designed and actual strength of concrete is done through the VCMP } \rightarrow \text { VCMP notification PASS or FAIL. } \\
\text { - The compressive strength of concrete samples (cubes or cylinders), tested in a laboratory for every batch of concrete used in } \\
\text { the manufacturing plant, is compared with the design specifications through the VCMP } \rightarrow \text { VCMP notification PASS or FAIL. }\end{array}$ \\
\hline 3 & On-site activities & $\begin{array}{l}\text { On-site activities for the precast concrete elements start when the element leaves the precast concrete manufacturing plant. } \\
\text { - A tag (e.g. barcode or RFID), assigned to the element at the manufacturing stage, is scanned at all main stages of the on-site } \\
\text { activities } \rightarrow \text { VCMP notification ELEMENT READY, DELIVERED TO SITE, INSTALLED, etc. }\end{array}$ \\
\hline $3 a$ & Installation & $\begin{array}{l}\text { - The 3D scanning (compared with BIM) is utilised to enable precast concrete element installation in a correct position, level and } \\
\text { - Ungles } \rightarrow \text { VCMP notification PASS or FAIL. } \\
\text { elilising embedded sensors (i.e. thermistors and strain gauges) at the stage of construction/installation of the precast concrete } \\
\text { VCMP would send a warning to the site/design engineer } \rightarrow \text { VCMP WARNING notification. } \\
\text { - Once a particular element is installed, the tag is scanned and a notification is sent to VCMP } \rightarrow \text { VCMP notification ELEMENT } \\
\text { INSTALLED. This notification may be useful, e.g. to trigger the need for an airtightness test. }\end{array}$ \\
\hline 4 & Operation & $\begin{array}{l}\text { - Embedded sensors (i.e. thermistors and strain gauges) and other measured data (e.g. weather data, building management } \\
\text { system (BMS) data) allow for the monitoring of the structural and environmental performance of the building, which can be } \\
\text { compared (through the VCMP) with the numerical models (developed at the design stage), in order to assess building's } \\
\text { performance "as designed" vs. "as built" } \rightarrow \text { VCMP notification PASS or FAIL. } \\
\text { - When the information about the building structure is needed (e.g. for audit/retrofit purposes or at the end of life for the } \\
\text { disassembly/recycling purposes), a tag, assigned to the element at the manufacturing stage, is scanned and the information can } \\
\text { be accessed from the VCMP. }\end{array}$ \\
\hline
\end{tabular}

laboratory testing) to support quality inspections during the whole life cycle of the building (Figure 5).

This research utilised a number of sensors embedded in the precast and in situ parts of the concrete floor slabs in the HBB (Figure 6), in order to monitor the structural and environmental performance of these slabs. Sensors were embedded in the second (East and West wing - thermistors and strain gauges, Figure 3) and third-floor slabs (West wing - thermistors only) of the HBB, and the first installation of sensors took place in June 2015. The sensors embedded in the HBB floor slabs included:

- IP68 rated thermistor sensors (ATC Semitec, 2014), which are capable of measuring concrete temperature in the range of between $-60 /+150^{\circ} \mathrm{C}$ with a $1 \%$ tolerance (Figure 7).

- Vibrating wire (VW) gauges (Gage Technique, 2014), which are capable of measuring strain and temperature of concrete. The strains can be measured in a range greater than 3000 microstrain with a resolution better than 1 microstrain. The temperature can be measured in a range between $-20 /+80^{\circ} \mathrm{C}$ with an accuracy of $\pm 1^{\circ}$ C (Figure 8).
All embedded sensors have been continuously monitoring data since their installation in the precast elements. Two data acquisition systems (Campbell Scientific, 2014) were deployed in the $\mathrm{HBB}$, one in the East and one in the West wing of the building, in order to collect and store the monitored data.

\section{Design stage}

Numerical methods are commonly used to design the overall building structure, as well as its elements. These models can also be utilised to investigate the structural and environmental performance of building structural components, e.g. (Amadio, Bedon, Fasan, \& Pecce, 2017; Ožbolt, Bošnjak, Periškić, \& Sharma, 2014). The numerical models developed as part of smart precast concrete solutions included FE models representing structural behaviour of the precast concrete floor slabs in the HBB. These linear elastic FE models provided bending moment diagrams which ensured that proposed slabs structurally performed according to standards, guidelines and design intent.

These models allowed optimisation of the number of sensors required and their position. Later at the operation stage, strains measured in the floor slabs were converted to 


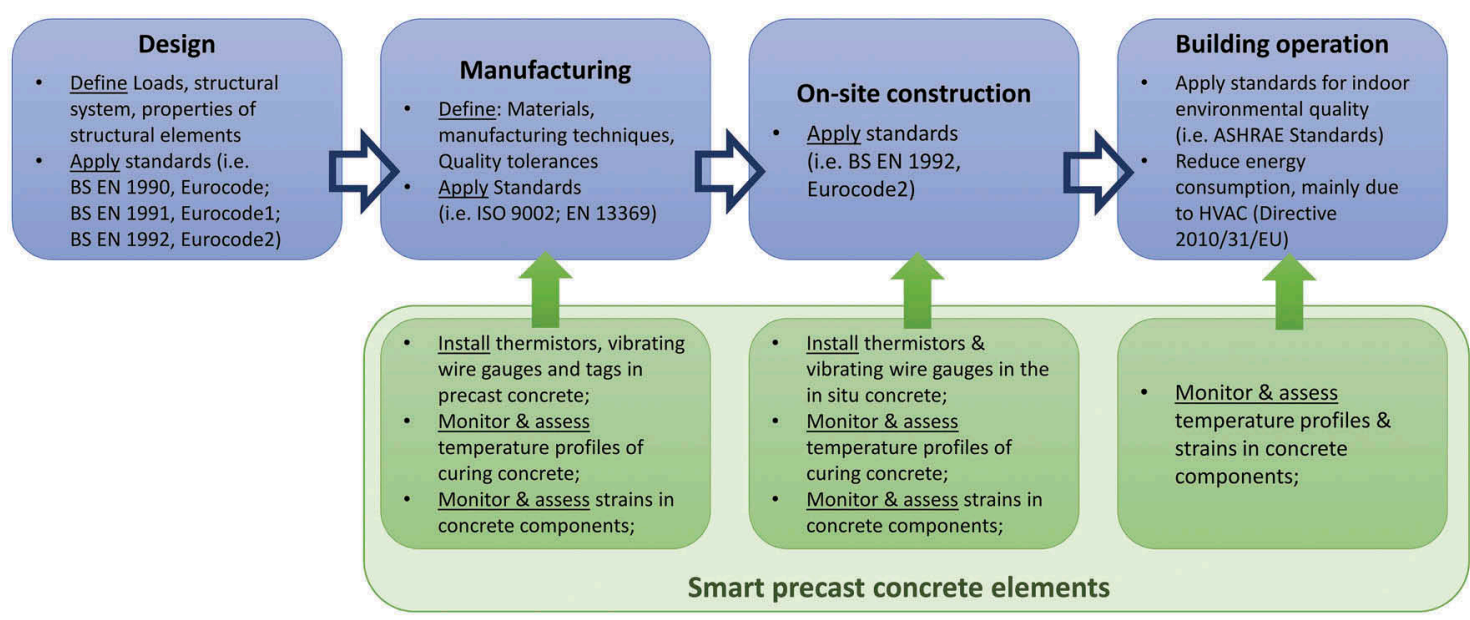

Figure 1. Smart precast concrete solutions quality checks at different building life cycle stages (Built2Spec project, 2017a).

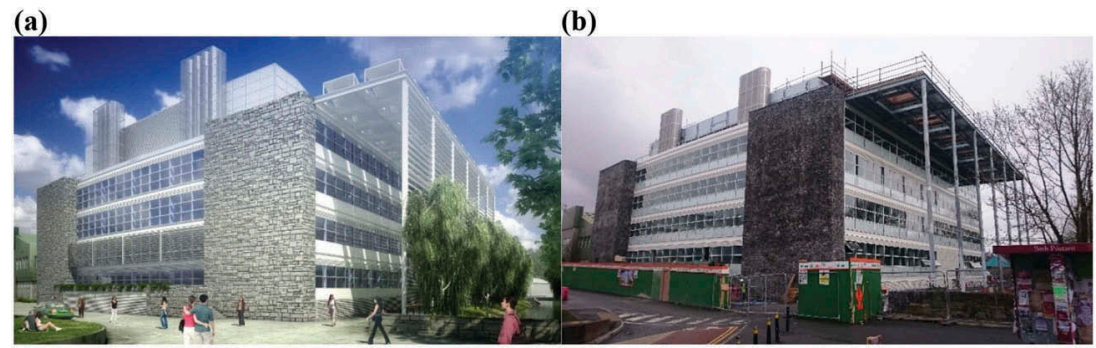

Figure 2. Human biology building at NUI Galway: (a) visualisation of the finished building (picture courtesy of BAM Ireland) and (b) construction phase.

bending moments and used to highlight differences between assumed and actual behaviour of these slabs.

Moreover, CFD models focusing on the heat transfer and heat storage in precast concrete elements (such as in Hajdukiewicz, Lebrene, \& Goggins, 2014) are currently being developed by the research team and validated with real-time temperature data from the HBB building.

Numerical models can enable scenario testing to estimate building performance under different loading/weather conditions, as well as change of purpose or retrofit, which can indicate potential faults and become part of building management operations.

Furthermore, BIM in precast concrete design and manufacturing has been utilised by a growing number of precast concrete manufacturers. Because of the specific requirements in precast concrete manufacturing, an element BIM is created, based on architectural design, using specialist software. Integration of a precast concrete element BIM into the project BIM (Figure 9) through the VCMP and BIMViewer (part of the open source BIM collective (IfcOpenShell, 2017)) enabled all measured/modelled data and quality checks to be associated with a particular precast concrete element.

\section{Manufacturing \& construction stage}

Concrete manufacturers are obliged to perform regular tests on the compressive strength of concrete. The compressive strength of concrete is measured by testing concrete samples (cubes or cylinders) in a laboratory for every batch of concrete used in the manufacturing plant. The measured strength of concrete is then compared with the design intent. High early temperature of concrete may have negative impacts on later strength of concrete. Utilising thermistors to monitor the temperature changes in concrete allows for better estimation of its future performance.

Figures 10-12 show the relationship between the early concrete temperature and curing time (for three different sets of $100 \mathrm{~mm} \times 100 \mathrm{~mm} \times 100 \mathrm{~mm}$ cubes of C40/50 concrete mix (Oran Pre-Cast Ltd, 2015), poured on 31.05.2017, 01.06.2017 and 07.06.2017) with a corresponding compressive strength tested at the end of the temperature measurement (approximately $12 \mathrm{~h}$ after the concrete pour, the samples were stored in the water with temperature of approximately $20^{\circ} \mathrm{C}$ ) in laboratory conditions. Comparing the temperature of curing concrete (obtained from the embedded sensors measurements), the curing time and concrete compressive strength gain allow for better control of the concrete curing process and any arising problems that can be immediately detected.

Predicting the temperature rise and temperature differentials is key parameters when determining the early-age behaviour of concrete elements and the potential for thermal cracking. Embedded sensors can be used to determine parameters, such as peak temperature and temperature differentials in concrete pours, to improve the accuracy of prediction models for early-age thermal cracking (Killeen, Goggins, \& Hajdukiewicz, 2018; Newell et al., 2016).

When delivered to site and installed, the precast concrete lattice girder plank must be temporarily supported by the props erected prior to the element installation. As the concrete frame progresses upwards, the floors constructed below the floor under construction are used to support the self-weight of the next floor. The decision on the backpropping sequence (for the floor structure at each level as 


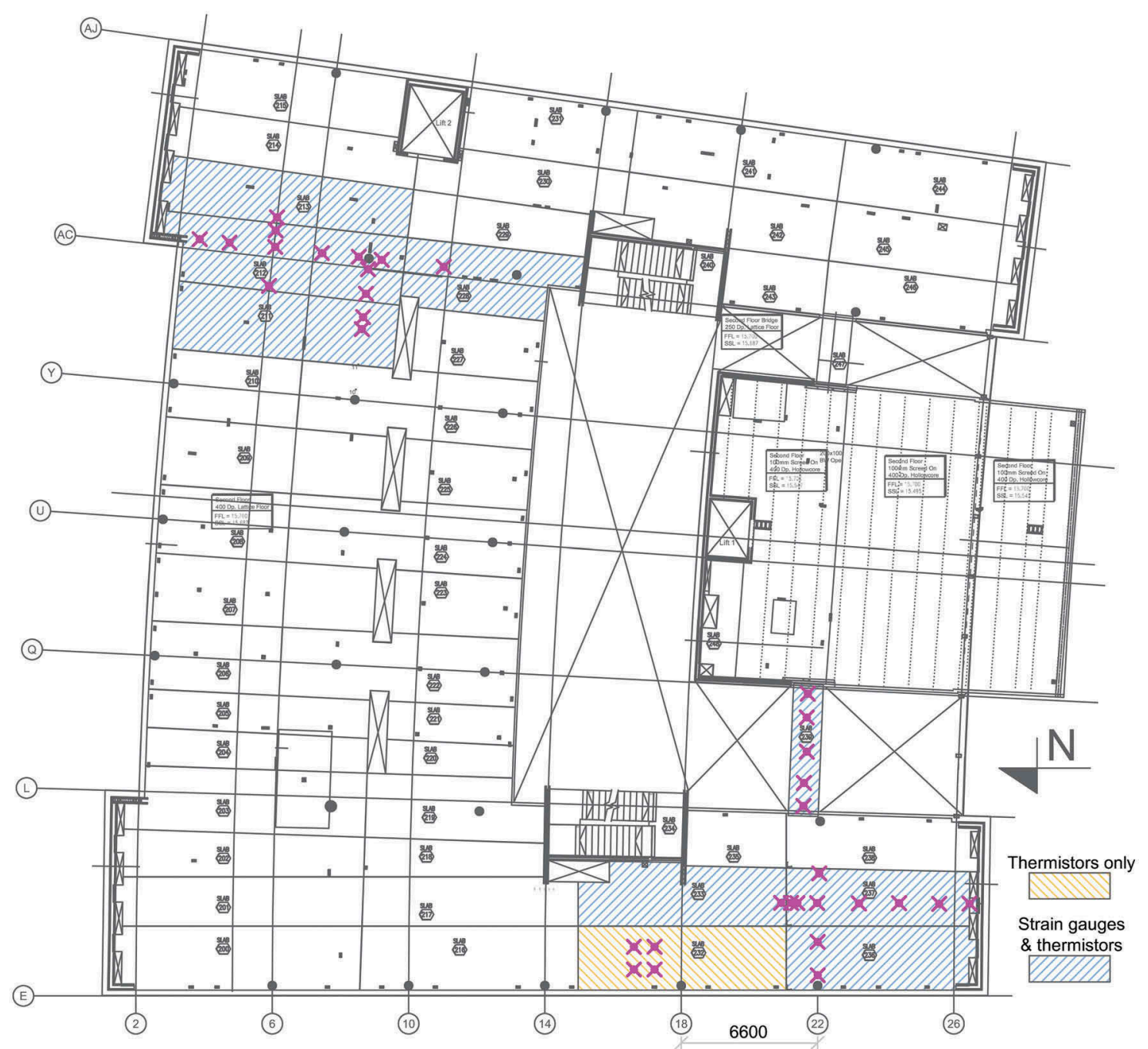

Figure 3. Second-floor plan of the HBB with instrumented areas marked (blue - strain gauges with thermistors, yellow - thermistors only, pink dot - sensor location).

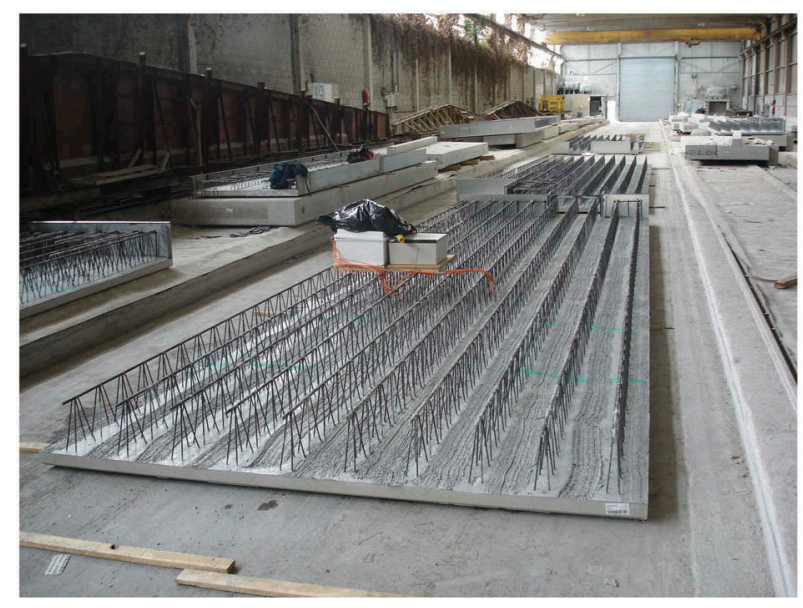

Figure 4. Lattice girder flat slab with embedded sensors and data acquisition system.

construction progresses) must ensure that the load from the wet concrete topping is transferred to a sufficient number of floors below guaranteeing the structure does not become overloaded. Once the compressive strength of the in-situ topping reaches a specified strength, the supporting props can be dropped allowing the floor slabs to support its own self-weight. Monitoring and analysing temperature and strain data from sensors embedded in precast concrete plank and the in-situ topping allow for better control of the strength gain of concrete and early estimation of potential cracking.

The current practice in precast concrete manufacturing is to assign a unique barcode identifier to all manufactured elements. Scanning the barcode automatically updates the database showing the current location/status of the precast concrete element. Typically, the barcode is only scanned when the element is stored within the manufacturing plant, when it leaves the manufacturing plant and when it is delivered to site. The barcodes are printed on a sticker and need to be placed on a concrete surface, in an accessible/ visible location for scanning, which limits their use. An alternative could be an RFID tag, which could be cast into concrete and, thus, utilised from the very beginning of the manufacturing process.

RFID tags could enhance the lean concepts in precast concrete manufacturing, support logistics and project management on site, aid in building retrofit, as well as enable design for disassembly and materials recycling (Figure 13). The RFID tag database could be linked with the BIM for better information management and construction progress visualisation. However, to date, suitable RFID tags to be used in precast concrete have not been found by the research team. Because of the smooth finish of precast concrete 

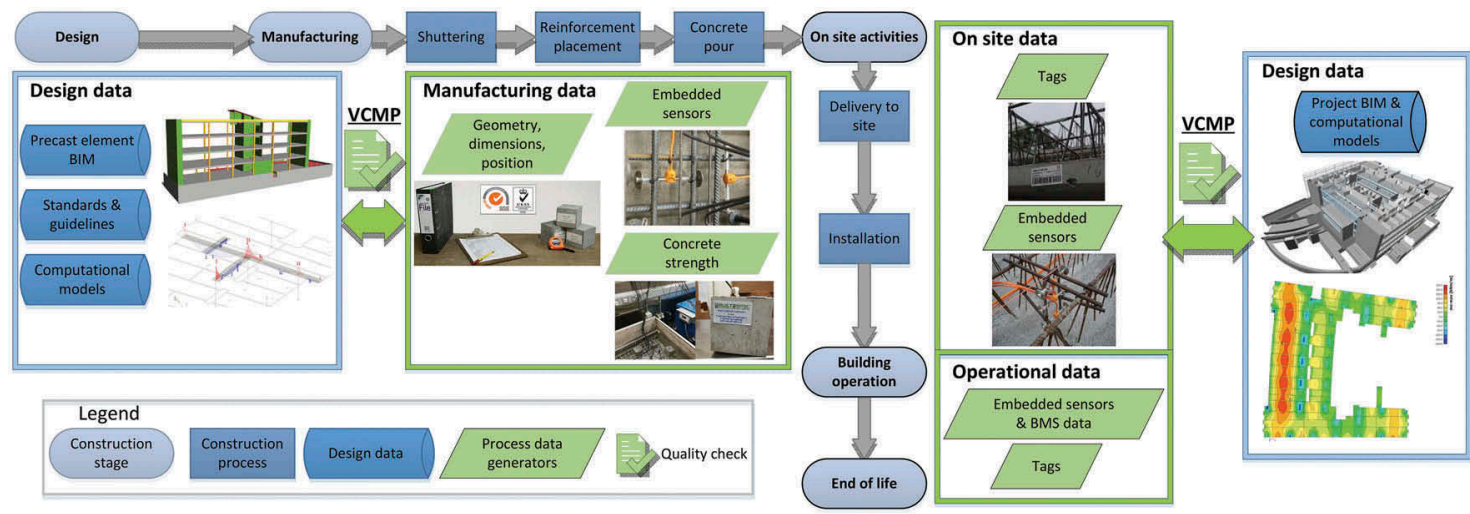

Figure 5. The use of smart precast concrete solutions in the HBB.

(a)

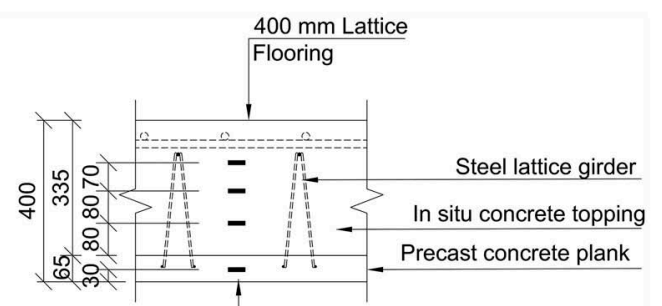

3No. thermistors in the in situ concrete \& 1 No. thermistor in the

precast plank

(b)

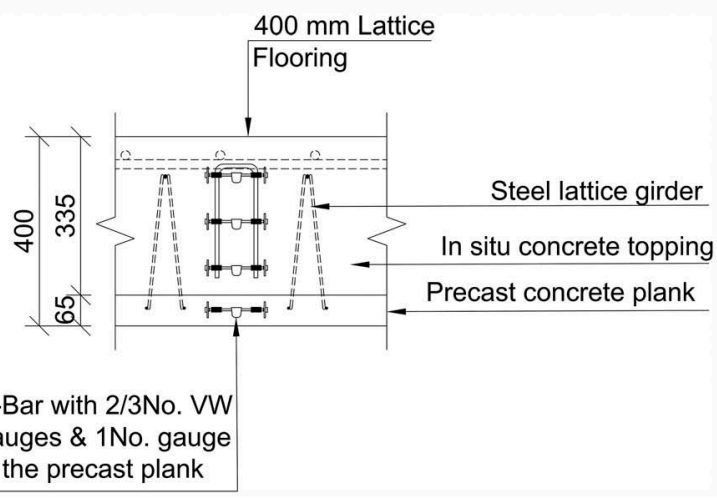

Figure 6. Sections of the hybrid concrete lattice girder flat slab showing location of embedded (a) thermistors and (b) VW gauges.

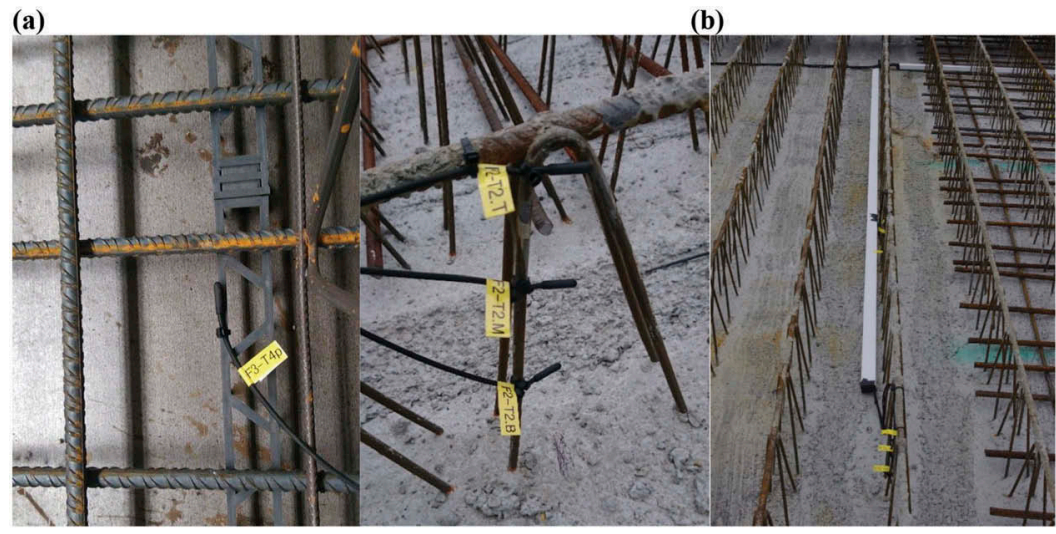

Figure 7. Thermistors embedded in the (a) precast and (b) in situ part of the concrete slabs in HBB.

elements, tags need to be embedded inside the precast element, not on the surface, which poses challenges with regards to the radio frequency of the electromagnetic wave and communication between the tag and the reader.
The current practice, for manufacturing and on-site installation of precast concrete elements, is by using electronic distance measurement (EDM) gridlines and measuring tapes. During the construction process, the dimensions, position, 


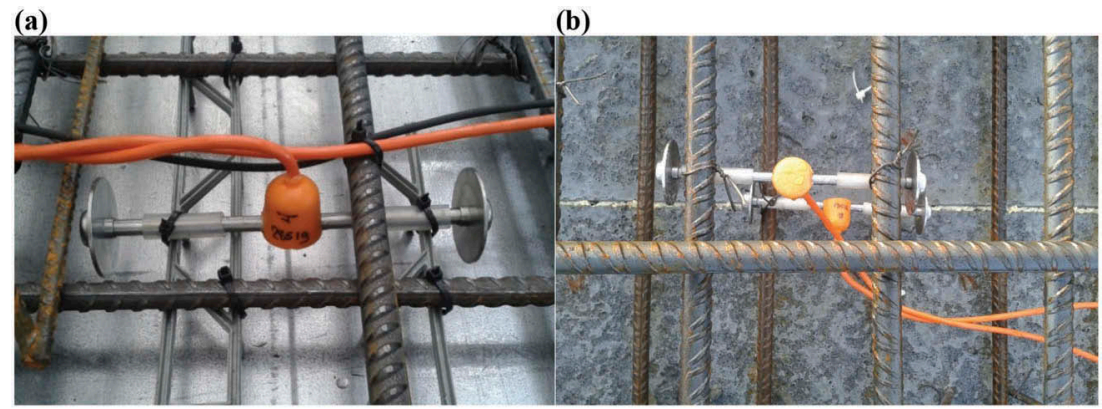

Figure 8. VW gauges embedded in the (a) precast and (b) in situ part of the concrete slabs in HBB.

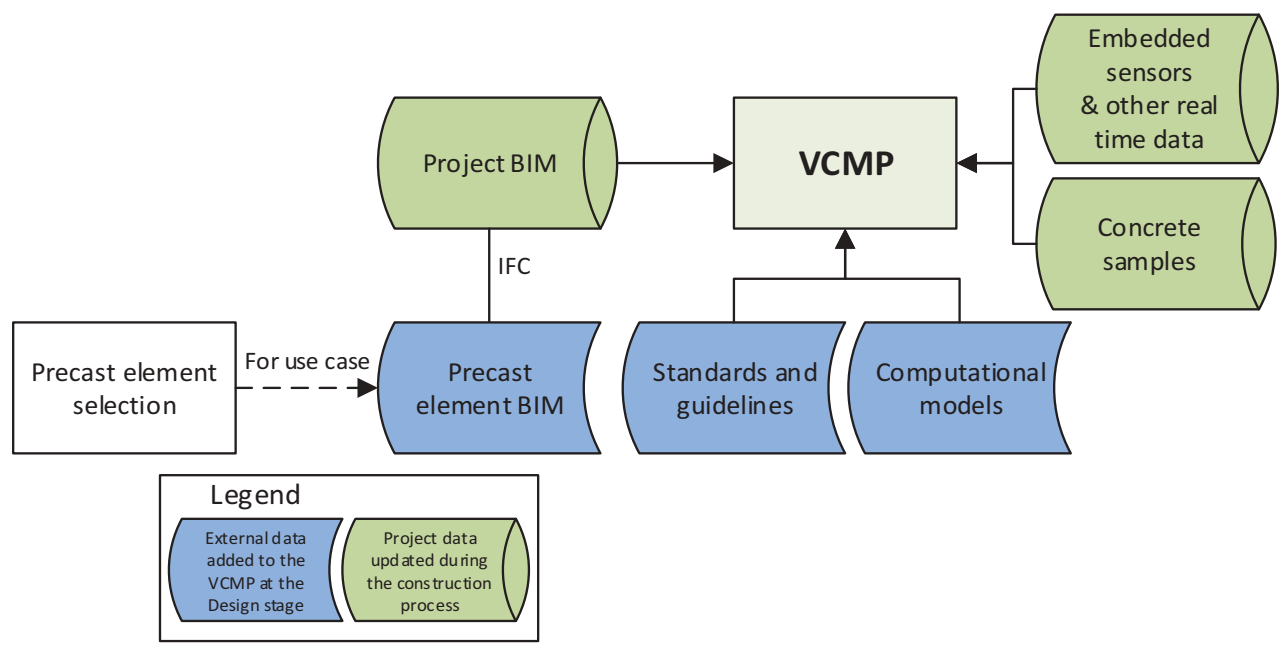

Figure 9. Proposed integration of smart precast concrete solutions into VCMP (Built2Spec project, 2017a).

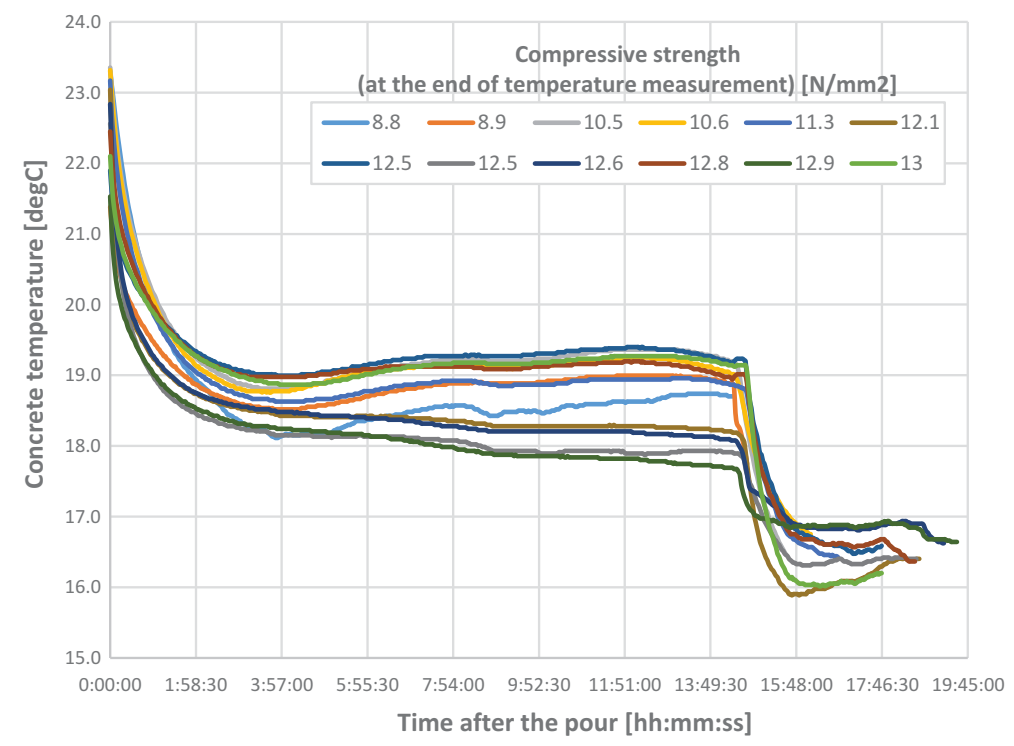

Figure 10. Concrete temperature measurement and compressive strength of cubes poured on 31.05.2017 (Built2Spec project, 2017a).

level, verticality/horizontality of precast concrete elements must be checked manually against the design drawings/specifications. 3D scanning aligned with BIM could be utilised at this stage, ensuring the required dimensional accuracy.

This research carried out preliminary scans, to test the performance of a laser scanner (Leica, 2017) for precast concrete structures. A sample structure was scanned, which consisted of a precast concrete foundation slab, 4 columns, 2 beams and 2 roof slabs (Figure 14). The scanner acquired $1,000,000$ points per second and each scan took $60 \mathrm{~s}$. The resolution of the scans was approximately 1 point every $2 \mathrm{~mm}$ and the accuracy was $\pm 1.5 \mathrm{~mm}$. The point cloud obtained through the 3D scan was then aligned with the previously created BIM. These preliminary tests showed that 


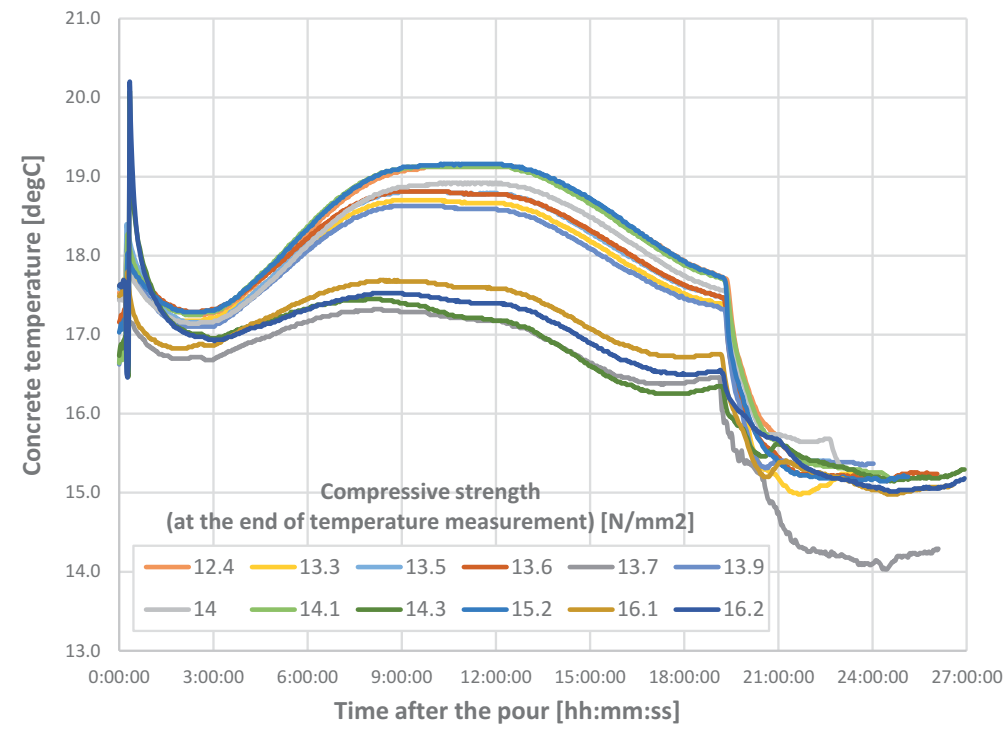

Figure 11. Concrete temperature measurement and compressive strength of cubes poured on 01.06.2017 (Built2Spec project, 2017a).

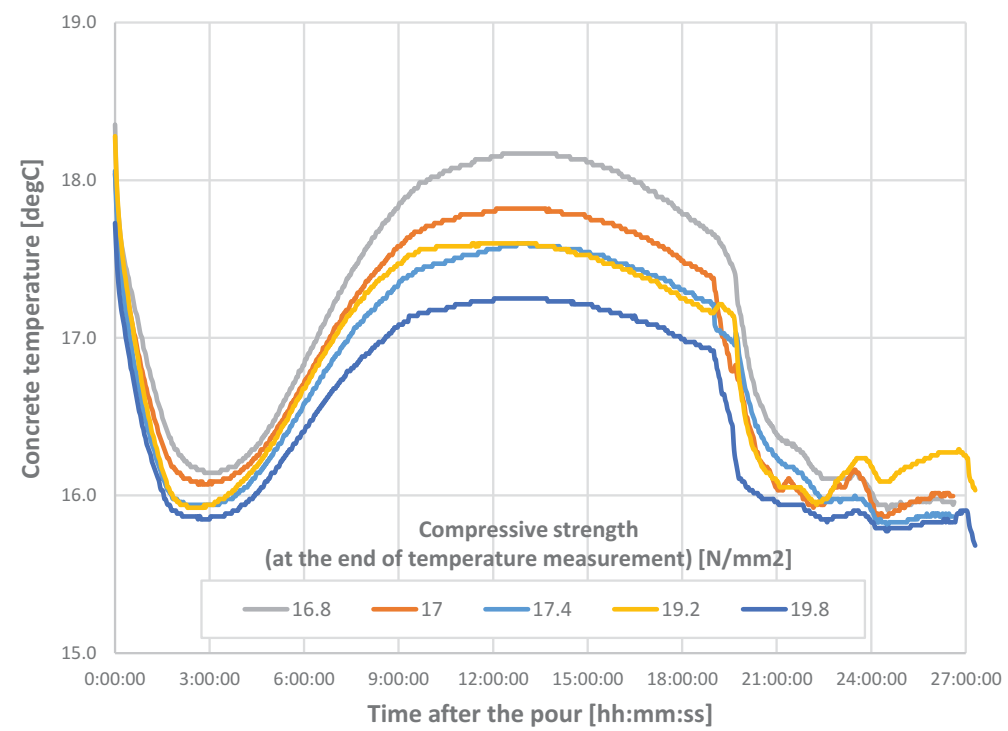

Figure 12. Concrete temperature measurement and compressive strength of cubes poured on 07.06.2017 (Built2Spec project, 2017a).

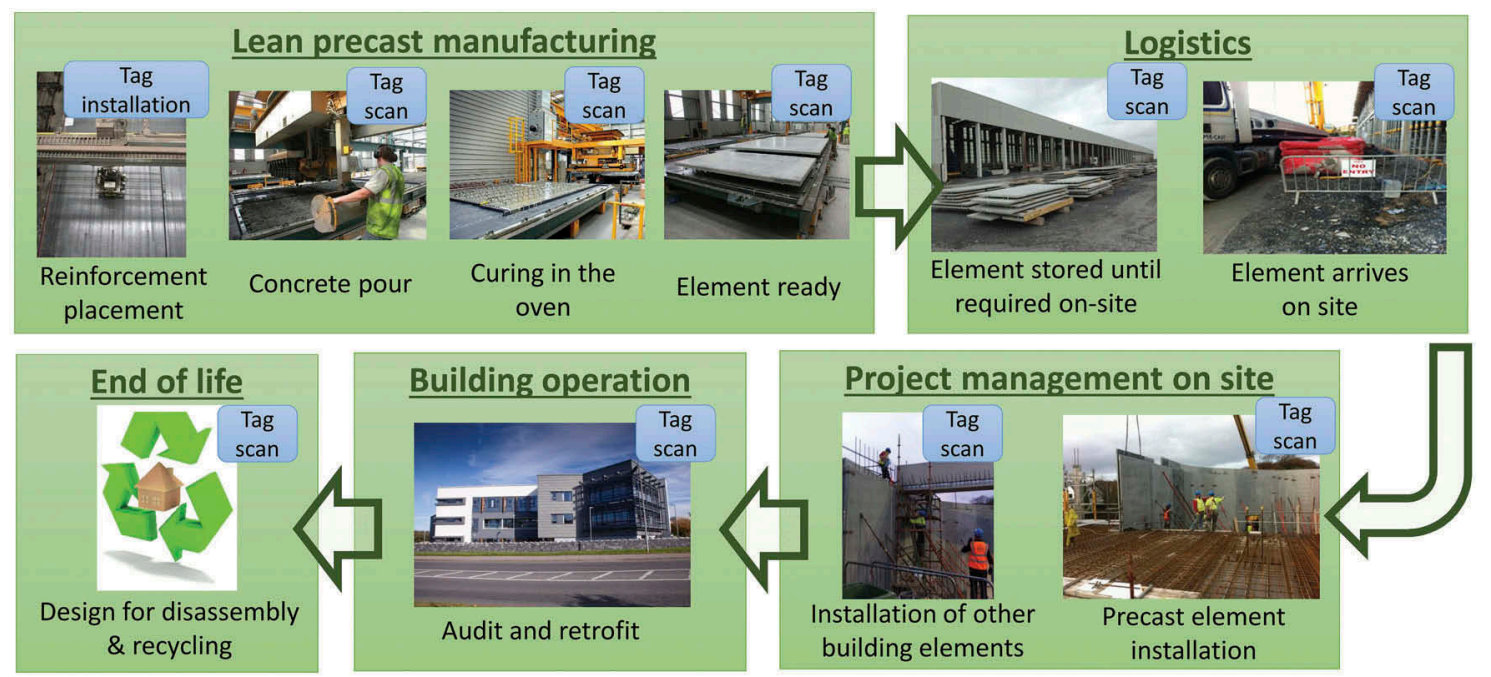

Figure 13. Proposed use of RFID tags during the whole life cycle of precast concrete building elements (Built2Spec project, 2017c). 
(a)

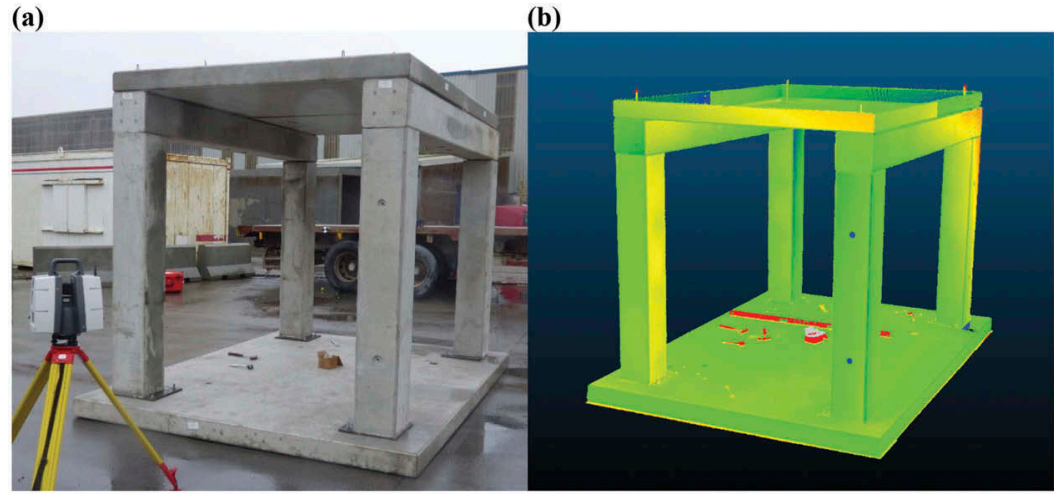

Figure 14. (a) Precast concrete structure erected for testing 3D scanning and BIM alignment and (b) point cloud survey from 3D laser scan (Built2Spec project, 2017a).

the scanner can be successfully utilised in precast concrete manufacturing/construction (more details on 3D scanning methods tested in Built2Spec project can be accessed at ref. (Built2Spec project, 2017b)).

\section{Operation}

The measured data obtained from the operating building (e.g. concrete temperature and strain, as well as weather and building management system (BMS) data), allow for evaluating of the structural and environmental performance of the building. Utilising embedded sensors provides damage detection (cracking, deflection, displacement, etc.), i.e. structural health monitoring and ensures durability and reliability of the structure as per design. The comparison of these measurements with the numerical models developed at the design stage allows the building's performance to be assessed "as designed" vs. "as built". Such an assessment could be valuable when there is a change of purpose of the building, planned retrofit, or different HVAC strategies are considered (thermal mass of concrete can be utilised in passive heating to reduce building's energy consumption). Furthermore, lessons learnt from the projects, where "as designed" vs. "as built" building performance was evaluated, can be actively taken into account in the future projects, leading to optimised and innovative design solutions.

The embedded sensors, supported by numerical models, provide rich information about the building performance, offering opportunities for better control strategies for operating buildings. This may lead to safer, healthier, more comfortable and productive indoor environments, at the same time ensuring the reduced/optimised energy consumption in buildings.

\section{Conclusions}

This paper describes an automated standard-based life cycle quality inspection methodology for smart precast concrete solutions in buildings. Starting with the design of the precast concrete element, through manufacturing, delivery to site, installation, building commissioning and operation until the end of life, the outputs of the proposed innovative technologies (such as real-time monitoring sensors, tags, BIM, 3D scanning techniques and computational methods for building performance evaluation) integrated and automated within the virtual construction management platform (VCMP) can enable continuous quality checks relevant and accessible to stakeholders involved in various stages of building life cycle.

This methodology was supported by the measurement framework for structural and environmental building performance monitoring that was designed and deployed in the demonstration Human Biology Building in Ireland, based on the lessons learnt from previous research work, i.e. (Hajdukiewicz et al., 2015; Newell et al., 2016). The environmental/structural performance monitoring of precast building elements:

- Commenced at the manufacturing stage, continued through the on-site installation, building commissioning and operation, and was underpinned by recognised quality management standards.

- Allowed geometry and location, strength gain and temperature of concrete to be continuously monitored and compared with design intent, standards and guidelines.

Following this, measured data were analysed and compared to numerical models, developed at design, to compare building performance "as designed" vs. "as built". This was done to ensure the design standards and guidelines for concrete systems were met under various conditions. The physical measurements collected during the project transferred directly into the VCMP, in order to provide a userfriendly quality check tool for engineers, building managers, contractors and other stakeholders.

\section{Highlights}

- Paper presents automated standard-based life cycle quality inspection methodology.

- Methodology ensures construction processes follow standard-based quality inspections.

- Novel technologies are incorporated in virtual construction management platform (VCMP).

- VCMP can be customised and put into the hands of various construction stakeholders.

- Embedded sensors are proposed to ensure quality of precast concrete products.

\section{Acknowledgments}

The project (Built2Spec) has received funding from the European Union's Horizon 2020 research and innovation programme under grant agreement No. 637221 . The sole responsibility for the content of 
this publication lies with the authors. It does not necessarily reflect the opinion of the European Union. Neither the EACl nor the European Commission are responsible for any use that may be made of the information contained therein. The second author would also like to acknowledge the funding received from the Science Foundation Ireland through the Career Development Award programme (Grant No. 13/ CDA/2200)

\section{Disclosure statement}

No potential conflict of interest was reported by the authors.

\section{Funding}

This work was supported by the Horizon 2020: EU Framework Programme for Research and Innovation [637221]; Science Foundation Ireland [13/CDA/2200].

\section{References}

Akinci, B., Boukamp, F., Gordon, C., Huber, D., Lyons, C., \& Park, K. (2006). A formalism for utilization of sensor systems and integrated project models for active construction quality control. Automation in Construction, 15(2), 124-138.

Amadio, C., Bedon, C., Fasan, M., \& Pecce, M. R. (2017). Refined numerical modelling for the structural assessment of steel-concrete composite beam-to-column joints under seismic loads. Engineering Structures, 138, 394-409.

Anil, E. B., Tang, P., Akinci, B., \& Huber, D. (2013). Deviation analysis method for the assessment of the quality of the as-is building information models generated from point cloud data. Automation in Construction, 35, 507-516.

Aram, S., Eastman, C., \& Sacks, R. (2013). Requirements for BIM platforms in the concrete reinforcement supply chain. Automation in Construction, 35, 1-17.

ATC Semitec. (2014). Thermal components. Online. Available at: www. atcsemitec.co.uk

Bosché, F. (2010). Automated recognition of 3D CAD model objects in laser scans and calculation of as-built dimensions for dimensional compliance control in construction. Advanced Engineering Informatics, 24(1), 107-118.

Brownjohn, J. M. W. (2007). Structural health monitoring of civil infrastructure. Philosophical Transactions. Series A, Mathematical, Physical, and Engineering Sciences, 365(1851), 589-622.

Built2Spec project. (2015). Built to specifications - tools for the 21st century construction worksite, EU H2020 grant agreement 637221. Online Available at: http://built2spec-project.eu/.

Built2Spec project. (2017a). D4.1 methodology for smart material selfinspection \& quality checks, Built to Specifications - Tools for the 21st Century Construction Site, EU H2020 Grant Agreement - 637221.

Built2Spec project. (2017b). D4.3 3D capture deliverable, Built to Specifications - Tools for the 21st Century Construction Site, EU H2020 Grant Agreement - 637221 .

Built2Spec project. (2017c). D7.2 real case (non-controlled environment) calibration and concurrent testing, Built to Specifications - Tools for the 21st Century Construction Site, EU H2020 Grant Agreement - 637221.

Campbell Scientific. (2014). Campbell scientific, Inc. Online. Available at: http://www.campbellsci.co.uk/.

CEN. (1999). Eurocodes EN 1990-1999, European Committee for Standardization, Brussels. Online. Available at: https://eurocodes.jrc ec.europa.eu/showpage.php?id=13

Chase, S. B. (2001). Smarter bridges, why and how? Smart Materials Bulletin, (2001(10), 9-13.

Chen, K., Lu, W., Peng, Y., Rowlinson, S., \& Huang, G. Q. (2015). Bridging BIM and building: From a literature review to an integrated conceptual framework. International Journal of Project Management, 33(6), 1405-1416.

Coutts, D., Wang, J., \& Cai, J. (2001). Monitoring and analysis of results for two strutted deep excavations using vibrating wire strain gauges. Tunnelling and Underground Space Technology, 16(2), 87-92.

Darbre, G. R., \& Proulx, J. (2002). Continuous ambient-vibration monitoring of the arch dam of mauvoisin. Earthquake Engineering \& Structural Dynamics, 31(2), 475-480.
ECTP. (2012). Building up infrastucture networks of a sustainable Europe. reFINE initiative, European Construction Technology Platform. Online Available at: http://ectp.ectp.org/cws/params/ectp/download_files/ 39D1547v3_Vision_Document_(pdf).pdf

Ergen, E., Akinci, B., \& Sacks, R. (2007). Tracking and locating components in a precast storage yard utilizing radio frequency identification technology and GPS. Automation in Construction, 16(3), 354-367.

European Commission. (2010). The directive 2010/31/EU of the European parliament and of the council of 19 May 2010 on the energy performance of buildings. Official Journal of the European Union, 153, 13-35. BG, ES, CS, DA, DE, ET, EL, EN, FR, IT, LV, LT, HU, $M T, N L, P L, P T, R O, S K, S L, F I, S V$.

Flanagan, R., Jewell, C., Lu, W., \& Pekericli, K. (2014). Auto-ID - Bridging the physical and the digital on construction projects. Bracknell: The Chartered Institute of Building (CIOB).

Gage Technique. (2014). Geotechnical and structural instrumentation. Online: Available at: http://www.gage-technique.com/

Goedert, J. D., \& Meadati, P. (2008). Integrating construction process documentation into building information modeling. Journal of Construction Engineering and Management, 134(7), 509-516.

Goodrum, P. M., McLaren, M. A., \& Durfee, A. (2006). The application of active radio frequency identification technology for tool tracking on construction job sites. Automation in Construction, 15(3), 292-302.

Ha, D. W., Park J. S., Kim J. M., \& Park H. S. (2014). Structural health monitoring of infrastructure using wireless sensor system. In N. Mitton, A. Gallais, M. Kantarci, \& S. Papavassiliou (Eds.), Ad Hoc Networks. ADHOCNETS 2015. Lecture Notes of the Institute for Computer Sciences, Social Informatics and Telecommunications Engineering 140 (pp. 228-234). Cham: Springer.

Hajdukiewicz, M., Byrne, D., Keane, M. M., \& Goggins, J. (2015). Real-time monitoring framework to investigate the environmental and structural building performance. Building and Environment, 86, 1-16.

Hajdukiewicz, M., Lebrene, J., \& Goggins, J. (2014). The environmental performance of a reinforced precast concrete slab with void forming system. In International Conference on Construction Materials and Structures (ICCMATS 2014). Johannesburg.

IfcOpenShell (2017). The open source ifc toolkit and geometry engine. Online. Available at: http://ifcopenshell.org/.

IPCA. (2005). Precast concrete: Frames guide. Dublin: Irish Precast Concrete Association.

ISO. (2008). Standard 9001: Quality management systems - Requirements. Geneva, Switzerland: International Organization for Standardization.

Jeong, Y. S., Eastman, C. M., Sacks, R., \& Kaner, I. (2009). Benchmark tests for BIM data exchanges of precast concrete. Automation in Construction, 18(4), 469-484.

Killeen, C., Goggins, J., \& Hajdukiewicz, M. (2018). Investigation into the correlation between curing temperature and compressive strength gain of concrete. In Civil Engineering Research in Ireland (CERI 2018) Conference, Dublin, Ireland.

Kim, M.-K., Wang, Q., Park, J.-W., Cheng, J. C. P., Sohn, H., \& Chang, C.-C. (2016). Automated dimensional quality assurance of full-scale precast concrete elements using laser scanning and BIM. Automation in Construction, 72(2), 102-114.

Lee, H. M., Kim, J. M., Sho, K., \& Park, H. S. (2010). A wireless vibrating wire sensor node for continuous structural health monitoring. Smart Materials and Structures, 19(5), 55004.

Lee, Y.-C., Eastman, C. M., \& Solihin, W. (2016). An ontology-based approach for developing data exchange requirements and model views of building information modeling. Advanced Engineering Informatics, 30(3), 354-367.

Leica. (2017). P40 - high-definition 3d laser scanning solution. Online. Available at: http://leica-geosystems.com/products/laser-scanners/ scanners/leica-scanstation-p40-p30

Li, H.-N., Li, D.-S., \& Song, G.-B. (2004). Recent applications of fiber optic sensors to health monitoring in civil engineering. Engineering Structures, 26(11), 1647-1657.

Li, H.-N., Ren, L., Jia, Z.-G., Yi, T.-H., \& Li, D.-S. (2016). State-of-the-art in structural health monitoring of large and complex civil infrastructures. Journal of Civil Structural Health Monitoring, 6(1), 3-16.

Lynch, J. P. (2007). An overview of wireless structural health monitoring for civil structures. Philosophical Transactions of the Royal Society, 365, 345-372.

Lynch, J. P., Law, K. H., Kiremidjian, A. S., Carryer, E., Farrar, C. R., Sohn, H., ... Wait, J. R. (2004). Design and performance validation of 
a wireless sensing unit for structural monitoring applications. Structural Engineering and Mechanics, 17(3-4), 393-408.

Mao, J., Chen, J., Cui, L., Jin, W., Xu, C., \& He, Y. (2015). Monitoring the corrosion process of reinforced concrete using BOTDA and FBG sensors. Sensors (Basel, Switzerland), 15(4), 8866-8883.

Matt, D. T., Dallasega, P., \& Rauch, E. (2014). Synchronization of the manufacturing process and on-site installation in ETO companies. Procedia CIRP, 17, 457-462.

McCarter, W. J., \& Chrisp, M. (2000). Monitoring water and ionic penetration into cover-zone concrete. American Concrete Institute (ACI) Materials Journal, 97(6), 668-674.

Mita, A. (1999). Emerging needs in Japan for health monitoring technologies in civil and building structures. In 2nd International Workshop on Structural Health Monitoring. Stanford University, CA.

Newell, S., Hajdukiewicz, M., \& Goggins, J. (2016). Real-time monitoring to investigate structural performance of hybrid precast concrete educational buildings. Journal of Structural Integrity and Maintenance (TSTR), 1(4), 147-155.

Nguyen, T., Venugopala, T., Chen, S., Sun, T., Grattan, K. T. V., Taylor, S. E., \& Long, A. E. (2014). Fluorescence based fibre optic $\mathrm{pH}$ sensor for the $\mathrm{pH} 10-13$ range suitable for corrosion monitoring in concrete structures. Sensors and Actuators B: Chemical, 191 498-507.

Oran Pre-Cast Ltd. (2015). Total pre-cast solutions. Online. Available at: http://www.oranprecast.ie/
Oskouie, P., Becerik-Gerber, B., \& Soibelman, L. (2016). Automated measurement of highway retaining wall displacements using terrestrial laser scanners. Automation in Construction, 65, 86-101.

Ožbolt, J., Bošnjak, J., Periškić, G., \& Sharma, A. (2014). 3D numerical analysis of reinforced concrete beams exposed to elevated temperature. Engineering Structures, 58, 166-174.

Pérez-Lombard, L., Ortiz, J., \& Pout, C. (2008). A review on buildings energy consumption information. Energy and Buildings, 40(3), 394-398.

Ranz, J. (2016). Monitoring of the curing process in precast concrete slabs: An experimental study. Construction and Building Materials, 122, 406-416.

Sørensen, K. B., Christiansson, P., \& Svidt, K. (2009). Prototype development of an ICT system to support construction management based on virtual models and RFID. Journal of Information Technology in Construction, 14, 263-288.

Uva, G., Porco, F., Fiore, A., \& Porco, G. (2014). Structural monitoring using fiber optic sensors of a pre-stressed concrete viaduct during construction phases. Case Studies in Nondestructive Testing and Evaluation, 2, p.27-37.

Valero, E., \& Adán, A. (2016). Integration of RFID with other technologies in construction. Measurement, 94, 614-620.

Wu, P., Low, S. P., \& Jin, X. (2013). Identification of non-value adding (NVA) activities in precast concrete installation sites to achieve low-carbon installation. Resources, Conservation and Recycling, 81, 60-70.

Yin, S. Y. L., Tserng, H. P., Wang, J. C., \& Tsai, S. C. (2009). Automation in construction. Developing a Precast Production Management System Using RFID Technology, 18(5), 677-691. 